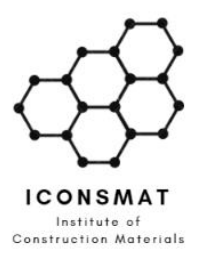

Content list available at ICONSMAT

Journal of Construction Materials

Journal homepage: www.iconsmat.com.au/publication
Article history:

Received 26 September 2020

Received in revised form

17 October 2020

Accepted 27 October 2020

Available online

2 January 2021

\title{
Predicting the creep coefficient of green concretes containing ground granulated blast furnace slag using hybridized multi-objective ANN and Salp swarm algorithm
}

\author{
Amirreza Kandiri ${ }^{1 *}$, Fahimeh Fotouhi ${ }^{2}$ \\ ${ }^{1}$ Institute of Construction Materials, Tehran, Iran \\ ${ }^{2}$ Department of computer engineering, Bu-Ali Sina University \\ *Corresponding author: E: amir.kandiri@iconsmat.com.au
}

\begin{abstract}
Using ground granulated blast furnace slag (GGBFS) in concrete mixtures that is known as supplementary materials, has both technical and economic advantages. The using of energy and greenhouse gas emission can be less if cement replaced by GGBFS in concrete mixtures. It is necessary to develop a detailed model in order to evaluate the creep coefficient of the concretes containing GGBFS because of important role of its value as a parameter in different design codes. In addition, it can save energy, cost, and time in comparison to direct laboratory-based measurements. In this research, to develop a model for the estimation of the creep coefficient of concretes containing GGBFS, Artificial neural network (ANN) was used. A multi-objective optimization method titled multi-objective slap swarm algorithm (MOSSA) was proposed to optimize the error and complexity of the developed ANN models. To develop predictive models of creep coefficient. Besides, one of the most used classification techniques to solve engineering problems which is The M5P model tree algorithm was used in order to develop predictive models of creep coefficient. The efficiency of the proposed model developed based on the ANN algorithm was compared with that of the model developed based on the M5P model tree technique with the help of several error measures. The findings from this research indicate that the M5P model tree and the proposed ANN model can successfully provide predictive tools for estimating the creep coefficient of concretes containing GGBFS with $13.36 \%$ and $1.79 \%$ mean absolute percentage error (MAPE), respectively. These values indicate that the proposed model based on ANN algorithm has superior efficiency compared to the one developed using M5P model tree.
\end{abstract}

DOI: 10.36756/JCM.v2.2.1r @2020 Institute of Construction Materials

\section{Keywords}

Concrete creep coefficient; Ground granulated blast furnace slag; Artificial neural network; Multiobjective optimization; Salp swarm algorithm; M5P model tree 


\section{Introduction}

The most used building material is concrete, which is made mainly from ordinary Portland cement, aggregates, and water. Studies show producing cement is one of the biggest reasons for greenhouse gases. In fact, in producing each ton of cement, almost a ton of $\mathrm{CO} 2$ produces [1-5]. This phenomenon has become one of the biggest problems in construction. Using supplementary cementitious materials (SCMs) as a replacement for cement can reduce the need for cement, and then as a result, the CO2 emission that is caused by construction is decreased. At first, SCMs were used to decline the use of cement, but further studies showed they could improve the durability of concrete and its mechanical properties[6].

Ground granulated blast furnace slag (GGBFS) is one of these SCMs, which is produced in the process of pig iron manufacturing, and it is made of $\mathrm{CaO}$ (30-50\%), $\mathrm{SiO} 2$ (28-38\%), Al2O3 (8-24\%), $\mathrm{MgO}$ (1-18\%) [7-9]. Because GGBFS changes fresh and hardened concrete properties, there is a need to develop a model that specially designed for the purpose of predicting mechanical properties of concrete with GGBFS such as its creep coefficient.

Artificial intelligence (Al) can be used to estimate concrete behavior and its mechanical tools. Artificial neural networks (ANN) is an Al tool, which has more usage for that matter. However, it does not predict the exact value and it has error. There are some methods, which can reduce this error, and using metaheuristic algorithms such as genetic algorithm and particle swarm optimization. The other parameter that affects ANN accuracy is its architecture. However, having an accurate network cost a lot of time and energy, and sometimes there is no need for this accuracy and tolerance because of its cost. Therefore, two parameters are needed to be optimized, accuracy and complexity of the network. Hence, a multi-objective algorithm named multi-objective salp swarm algorithm (MOSSA) used to develop a series of networks with a variety of accuracy and complexity to let the user choose one of them considering their project limits[10].

There have been some studies that has been used the mentioned methods for predicting concrete mechanical properties such as compressive strength (CS), elastic modulus (EM), flexural strength (FS), split tensile (ST), and creep coefficient (CC), which are represented in Table 1.

Table $1 \mathrm{~A}$ list of previous research on the applications of various Al-based techniques in concrete industry.

\begin{tabular}{lll}
\hline \hline Concrete type & Property & Al model \\
\hline \hline $\begin{array}{l}\text { Concretes containing } \\
\text { GGBFS }\end{array}$ & CS & ANN with MOSSA, M5P[11] \\
\hline $\begin{array}{l}\text { Concrete containing waste } \\
\text { foundry sand }\end{array}$ & CS, FS, EM, & M5P[12] \\
\hline $\begin{array}{l}\text { Normal and high-strength } \\
\text { concretes with fly ash } \\
\text { and/or GGBFS }\end{array}$ & CS & M5P [13], Fuzzy logic [14], ANN [6,14-17] \\
\hline $\begin{array}{l}\text { High-performance concrete } \\
\text { made with copper slag and } \\
\text { nanosilica }\end{array}$ & CS & Regression analysis and ANN [18] \\
\hline
\end{tabular}




\begin{tabular}{|c|c|c|}
\hline $\begin{array}{l}\text { Concretes containing fly ash } \\
\text { and/or GGBFS }\end{array}$ & CS & ANN [14] \\
\hline $\begin{array}{l}\text { Concretes containing } \\
\text { construction and demolition } \\
\text { waste }\end{array}$ & CS & ANN [19] \\
\hline $\begin{array}{l}\text { Concretes containing fly ash } \\
\text { and silica fume }\end{array}$ & CS & ANN [20] \\
\hline $\begin{array}{l}\text { Self-compacting concrete } \\
\text { (SCC) }\end{array}$ & CS & ANN $[21,22]$ \\
\hline Silica fume concrete & CS & ANN [23], Fuzzy logic [23], ANN [24], BBP [25] \\
\hline Lightweight concrete & CS & ANN $[26,27]$ \\
\hline $\begin{array}{l}\text { Environmentally friendly } \\
\text { concrete }\end{array}$ & CS & Hybrid ultrasonic-neural prediction [28], ANN [29], \\
\hline $\begin{array}{l}\text { Concrete containing } \\
\text { agricultural and } \\
\text { construction wastes }\end{array}$ & CS & ANN [30] \\
\hline $\begin{array}{l}\text { Normal and high- } \\
\text { performance recycled } \\
\text { aggregate concrete }\end{array}$ & $\begin{array}{l}\text { CS, EM, FS, } \\
\text { ST }\end{array}$ & multiple nonlinear regression and ANN [31] \\
\hline $\begin{array}{l}\text { Recycled aggregate } \\
\text { concrete }\end{array}$ & EM & $\begin{array}{l}\text { M5P [32], genetic programming, ABC programming, } \\
\text { and BBP [33], ANN, fuzzy TSK, RBF network, and SVR } \\
{[34]}\end{array}$ \\
\hline $\begin{array}{l}\text { Steel fiber-reinforced } \\
\text { concrete }\end{array}$ & ST & ANN, SVR, and M5P [35] \\
\hline SCC & EM & $\mathrm{BBP}$ and $\mathrm{ABCP}[36]$ \\
\hline $\begin{array}{l}\text { Concretes containing waste } \\
\text { foundry sand }\end{array}$ & $\begin{array}{l}\text { CS, EM, FS, } \\
\text { ST }\end{array}$ & M5P [37] \\
\hline
\end{tabular}

\section{Data collection}

To establish the models for the forecast of the creep coefficient, in this research, an exhaustive database counting 120 particular experiential records of cements made with GGBFS was gathered from the literature [38]. In all the specimens, the form of portland cement and curing conditions were kept unchanged. The single output parameter in this study was the cylinder ( 150 millimeters by 600 millimeters). creep coefficient (CC) of concrete. Seven potentially impressive factors were considered as input variables in three main categories, namely the amount of constituents in the concrete mix, cement type (CT) and the testing age (TA) of the concrete. The quantities of OPC, GGBFS, water (W), fine aggregate (FA) and coarse aggregate (CA) form the concrete components. Conversion factors were used to achieve the target elastic modulus for the experimental records for different types of specimens [52]. Fig. 1 shows the histograms of the input and the output variables. In addition, Table 2 provides the descriptive statistics for the obtained database. 

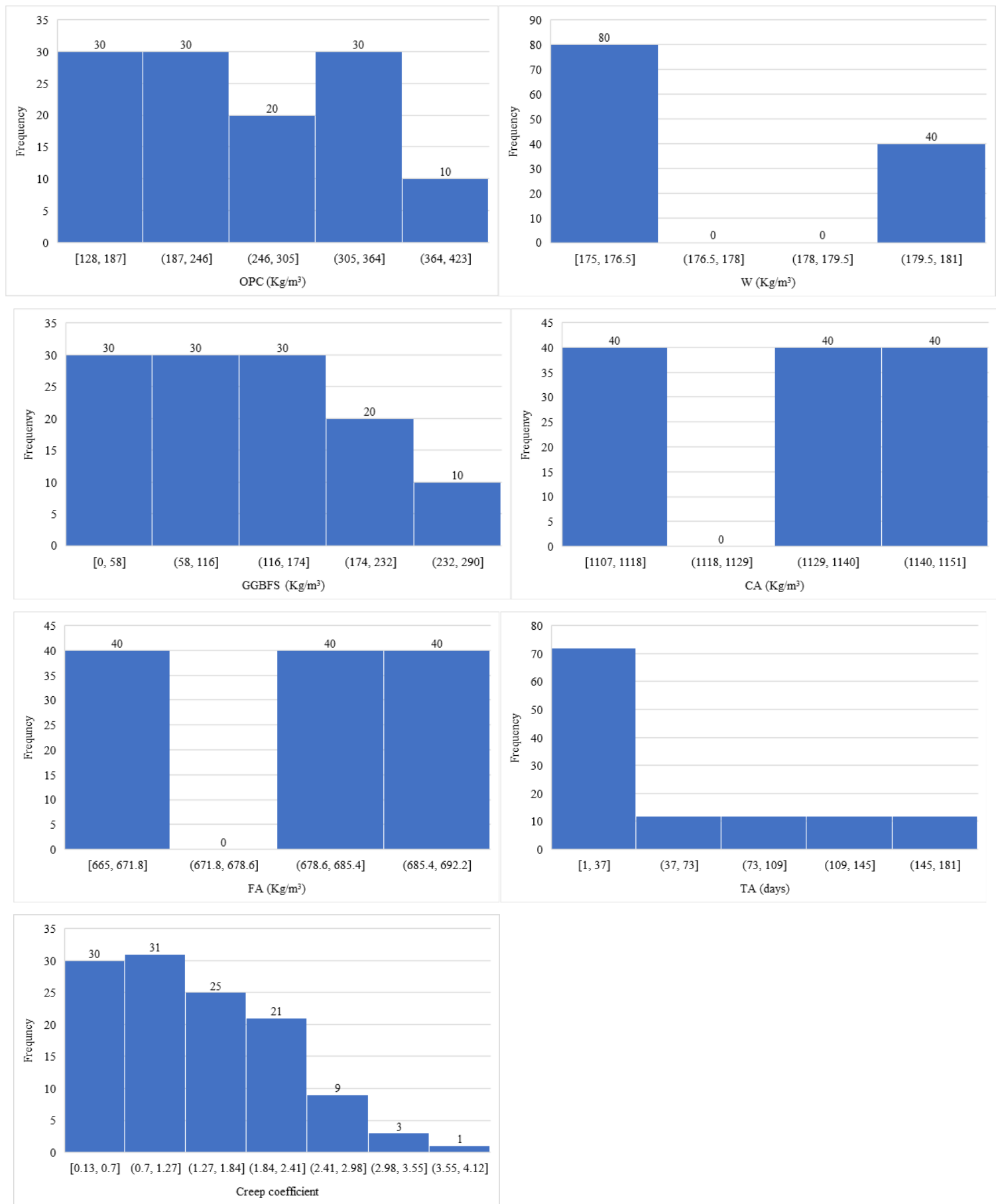

Figure 1 The histograms of input and the output variables. 
Table 2 Statistical values of input and output variables.

\begin{tabular}{cccccccc}
\hline Statistical values & $\begin{array}{c}\mathrm{C} \\
\left(\mathrm{Kg} / \mathrm{m}^{3}\right)\end{array}$ & $\begin{array}{c}\mathrm{W} \\
\left(\mathrm{Kg} / \mathrm{m}^{3}\right)\end{array}$ & $\begin{array}{c}\mathrm{GGBFS} \\
\left(\mathrm{Kg} / \mathrm{m}^{3}\right)\end{array}$ & $\begin{array}{c}\mathrm{CA} \\
\left(\mathrm{Kg} / \mathrm{m}^{3}\right)\end{array}$ & $\begin{array}{c}\mathrm{FA} \\
\left(\mathrm{Kg} / \mathrm{m}^{3}\right)\end{array}$ & $\begin{array}{c}\mathrm{TA} \\
(\text { Days })\end{array}$ & $\begin{array}{c}\mathrm{CC} \\
(\mathrm{MPa})\end{array}$ \\
\hline Minimum & 128.0 & 175.0 & 0.0 & 1107.0 & 665.0 & 1.0 & 0.1 \\
Maximum & 400.0 & 180.0 & 240.0 & 1145.0 & 688.0 & 150.0 & 3.6 \\
Mean & 249.7 & 177.0 & 107.0 & 1128.0 & 677.7 & 49.0 & 1.4 \\
Standard deviation & 83.4 & 2.2 & 80.7 & 15.8 & 9.5 & 50.6 & 0.8 \\
Skewness & 0.2 & 0.6 & 0.1 & -0.4 & -0.4 & 0.9 & 0.5 \\
Kurtosis & -1.1 & -1.5 & -1.3 & -1.5 & -1.5 & -0.7 & -0.5 \\
\hline
\end{tabular}

\section{Methodology}

Trial-and-error is the most utilized approach to evaluate the architecture of an ANN. The development of a model that can produce ANN models with various complexities and accuracies is seriously necessary because if there is a difference in the number of hidden layers and their neurons, the speed and precision of an ANN can difference. In this research, an ANN to establish a multi-objective artificial neural network (MOANN) [20] was combined with a multi-objective optimization algorithm named salp swarm algorithm (SSA) [53]. Various MOANN stages are shown in Fig. 2. Then the outputs of the M5P tree $[54,55]$ are compared to the MOANN outputs to measure the accuracy of the proposed model. 


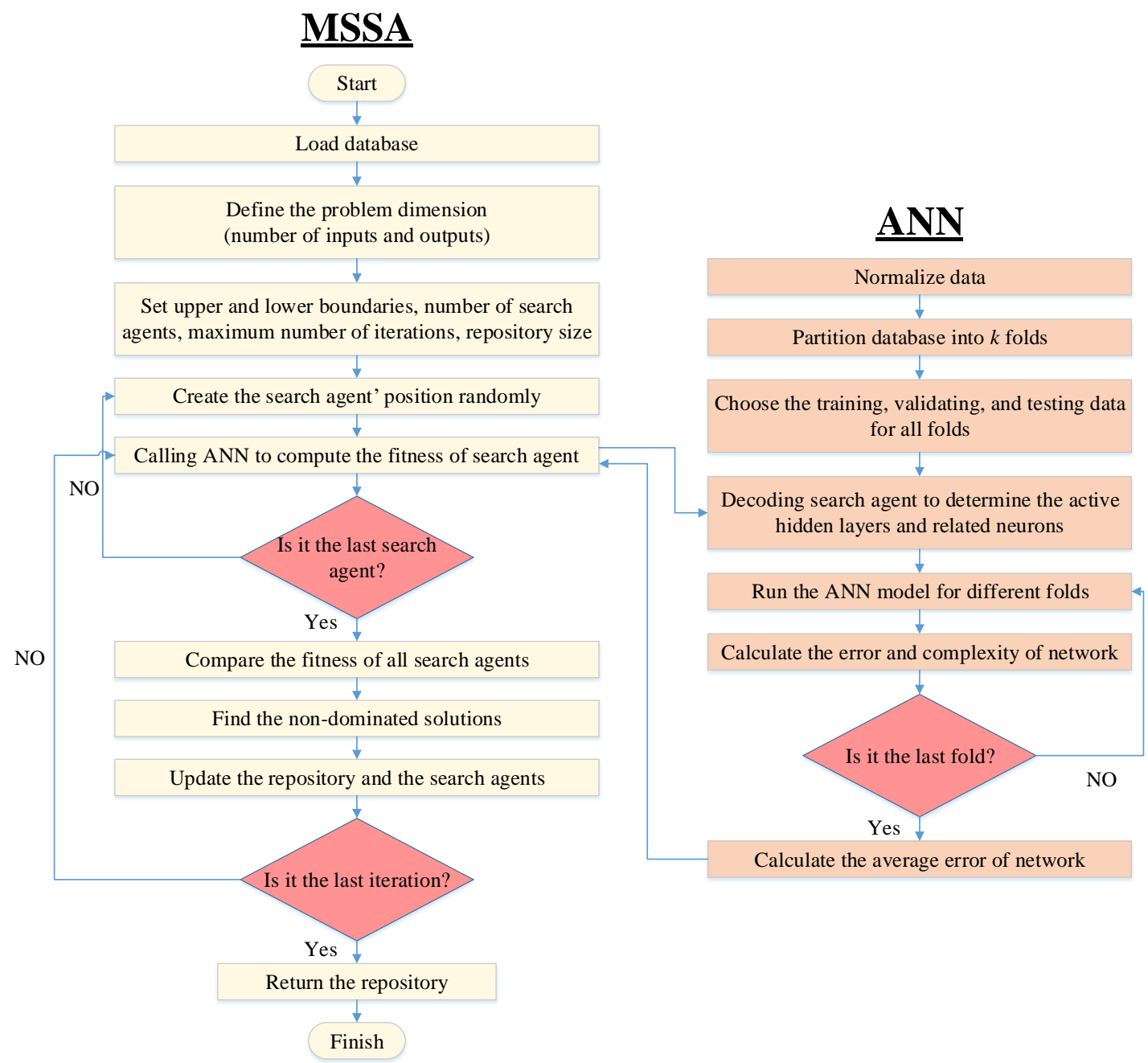

Figure 2 Different stages of the proposed MOANN

\section{Results and discussion}

Adjustment parameters including the maximum number of hidden layers, the maximum number of neurons in each hidden layer, the activation function type in hidden and output layers, the ANN training method, the total runs number, the number of maximum iteration, the number of salps, and the size of the repository should be calculated before running the proposed model. With the help of trial-anderror technique, all these parameters were acquired, and they can be seen in Table 3. 
Table 3 Adjustment parameters of the proposed model.

\begin{tabular}{ll}
\hline Parameters & Values \\
\hline Maximum number of hidden layers & 3 \\
Maximum number of neurons in each hidden layer & 16 \\
Hidden layers' activation function & Hyperbolic tangent sigmoid \\
Output layer's activation function & Linear \\
ANN training algorithm & Levenberg-Marquardt \\
Number of total runs & 10 \\
Maximum iteration number & 100 \\
Salp number & 30 \\
Repository size & 50
\end{tabular}

After 10 times of running the model, the best Pareto front which is provided in Fig. 3 was achieved. The horizontal and vertical axes in Fig. 3 provide complexity and OBJ respectively which are two objective functions. The number of 150,000 ANN models with various architectures was developed to achieve the Pareto front, and ultimately 12 non-dominated salps depicting the optimum ANN models were reached. It can be understood from Fig. 3 that when the OBJ value goes down, the complexity grows, and it means that more accurate creep coefficient of concrete containing GGBFS can be estimated by the ANN models with more complicated architectures. 


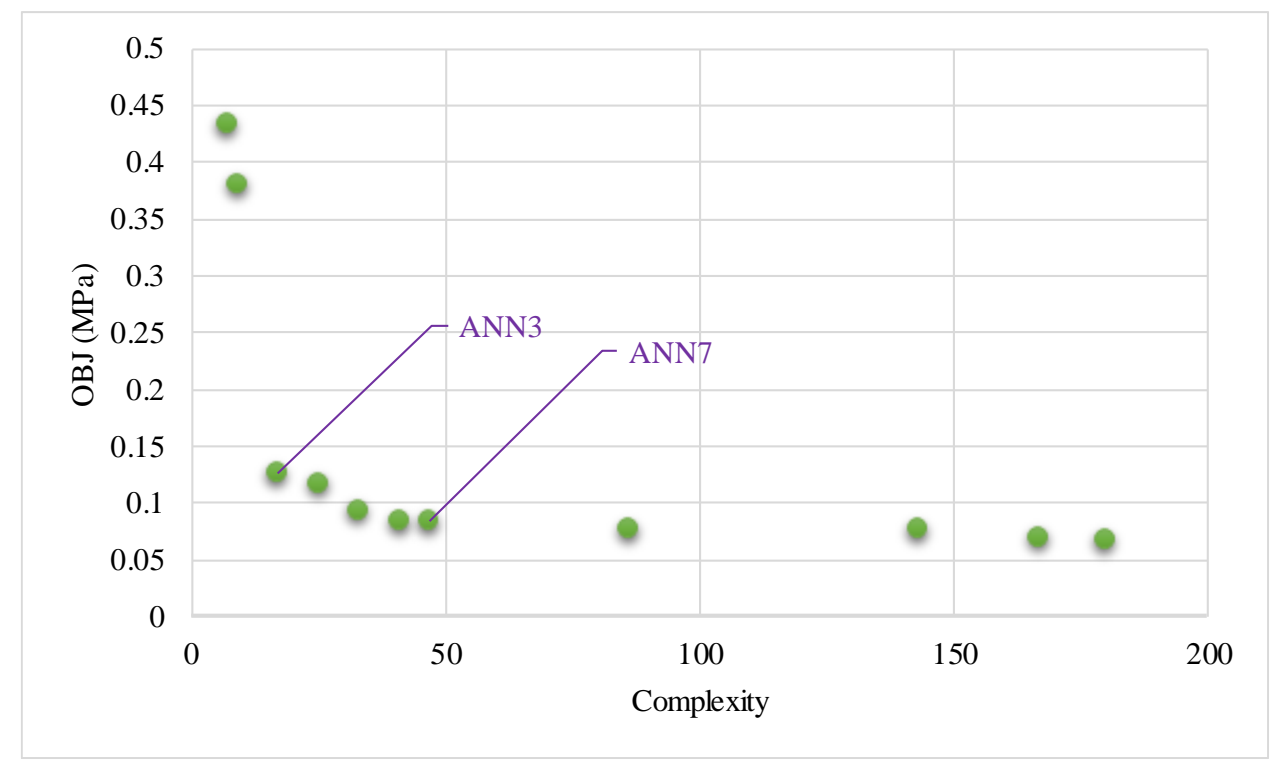

Figure 3 Pareto front of the proposed model.

Statistical metrics other than those listed in the previous section were used to compare the performance of the developed models with various architectures. These statistical metrics were scatter index (SI), mean bias error (MBE), and mean absolute percentage error (MAPE), which are defined as follows:

$\mathrm{SI}=\mathrm{RMSE} / \overline{\mathrm{E}}$

$\operatorname{MBE}=\frac{1}{\mathrm{P}} \sum_{\mathrm{i}=1}^{\mathrm{P}}\left(\mathrm{M}_{\mathrm{p}}-\mathrm{E}_{\mathrm{p}}\right)$

MAPE $=\frac{100}{P} \sum_{i=1}^{P} \frac{M_{P}-E_{P}}{M_{P}}$

Where $\bar{E}$ is the average value of the outcomes of the experiment and other factors are as described previously. An ANN model has an "excellent performance" if $\mathrm{SI}<0.1$, a "good performance" if $0.1<\mathrm{SI}$ $<0.2$, a "fair performance" if $0.2<\mathrm{SI}<0.3$, or a "poor performance" if $\mathrm{SI}>0.3$ [56]. For all the data, Table 4 presents the architectures, statistical indicators, and complexities of the optimal ANN models.

Table 4 Non-dominated salps information for all data.

\begin{tabular}{|c|c|c|c|c|c|c|c|c|c|}
\hline ANN & Architecture & $\begin{array}{l}\text { OBJ } \\
(\mathrm{MPa})\end{array}$ & $\begin{array}{l}\text { RMSE } \\
\text { (MPa) }\end{array}$ & $\begin{array}{l}\text { MAPE } \\
(\%)\end{array}$ & $\begin{array}{l}\text { MAE } \\
(\mathrm{MPa})\end{array}$ & $\mathrm{R}$ & SI & $\begin{array}{l}\mathrm{MBE} \\
(\mathrm{MPa})\end{array}$ & Complexity \\
\hline ANN1 & $6-1$ & 0.434 & 0.304 & 38.387 & 0.238 & 0.926 & 0.220 & -0.013 & 7 \\
\hline ANN2 & 6-1-1 & 0.380 & 0.369 & 29.089 & 0.230 & 0.889 & 0.266 & -0.020 & 9 \\
\hline ANN3 & $\underline{6-2-1}$ & 0.125 & 0.146 & $\underline{12.458}$ & 0.064 & $\underline{0.983}$ & $\underline{0.105}$ & 0.002 & $\underline{17}$ \\
\hline$\overline{A N N 4}$ & $6-3-1$ & 0.117 & 0.149 & $\overline{11.301}$ & 0.044 & 0.983 & 0.108 & -0.016 & $\overline{25}$ \\
\hline ANN5 & $6-4-1$ & 0.093 & 0.110 & 9.296 & 0.057 & 0.991 & 0.079 & -0.001 & 33 \\
\hline ANN6 & $6-5-1$ & 0.084 & 0.062 & 6.245 & 0.045 & 0.997 & 0.044 & 0.003 & 41 \\
\hline ANN7 & $\underline{6-3-5-1}$ & 0.084 & $\underline{0.055}$ & 4.789 & 0.041 & $\underline{0.998}$ & $\underline{0.040}$ & $\underline{-0.003}$ & $\underline{47}$ \\
\hline$\overline{\text { ANN8 }}$ & $6-3-6-5-1$ & 0.076 & 0.049 & 4.829 & 0.037 & 0.998 & $\overline{0.035}$ & 0.001 & 86 \\
\hline ANN9 & $6-11-5-1$ & 0.076 & 0.038 & 3.119 & 0.024 & 0.999 & 0.028 & -0.001 & 143 \\
\hline ANN10 & $6-5-9-7-1$ & 0.070 & 0.044 & 4.390 & 0.031 & 0.998 & 0.032 & -0.007 & 167 \\
\hline ANN11 & $6-5-10-7-1$ & 0.068 & 0.039 & 3.491 & 0.025 & 0.999 & 0.028 & 0.001 & 180 \\
\hline
\end{tabular}


As it shown in Fig. 3, two networks (ANN3 and ANN7) were chosen for further investigation because of the slight decline in the next error of the next ANNs in contrast to the huge growth in their number of links. Fig. 4 shows the structure of ANN3, which has two neuron in its only hidden layer and ANN7, which has three and five neuron in the first and the second hidden layer, respectively. ANN1 is the simplest network with seven links in contrast to ANN11, which has 180 links and is the most complex one. ANN3 and ANN7 have 17 and 47 links, respectively. The OBJ of ANN1 is the highest by the value of $0.434 \mathrm{MPa}$ while ANN3 and ANN7 have OBJ value of 0.125 and 0.084 , respectively, and ANN1 has the OBJ value of $0.068 \mathrm{MPa}$, which is the lowest. The RMSE of ANN1 is equal to 0.304 , which is the highest value among the networks and the same value of ANN3, ANN7, and ANN11 are 52\%, 82\%, and 87\% lower than that of ANN1. According to MAPE, ANN11 is the most accurate network with the MAPE value of 3.491\% and this value of ANN7, ANN3, and ANN1 are around 1.3, 3.5, and 11 times more than that of ANN11. ANN11 has the MAE value of 0.025 , and ANN7, ANN3, and ANN1 are less accurate by 0.016 , 0.039 , and $0.213 \mathrm{MPa}$. R-value indicates how much experimental and predicted values are close and it ranges between zero and one. Moreover, the higher this value gets, the closer the predicted and experimental values are, and 10 networks out of 11 have R-value more than 0.9. Based of SI indicator ANN1 has a fair performance and ANN3 has a good one while ANN7 and ANN11 have an excellent performance. According to MBE, ANN1 and ANN7 under estimate the creep coefficient of the concrete containing GGBFS while ANN3 and ANN11 over estimate this value. The weights and biases of the ANN3 and ANN-7 models are given in the appendix.

\begin{tabular}{|c|c|c|c|c|c|}
\hline $\begin{array}{l}\text { Input } \\
\text { layer }\end{array}$ & $\begin{array}{c}\text { Hidden } \\
\text { layer }\end{array}$ & $\begin{array}{l}\text { Output } \\
\text { layer }\end{array}$ & $\begin{array}{l}\text { Input } \\
\text { layer }\end{array}$ & $\begin{array}{l}\text { Hidden } \\
\text { layers }\end{array}$ & $\begin{array}{c}\text { Output } \\
\text { layer }\end{array}$ \\
\hline $\mathbf{i}$ & $h_{1}$ & o & $\mathbf{i}$ & $\mathbf{h}_{1}$ & o \\
\hline
\end{tabular}

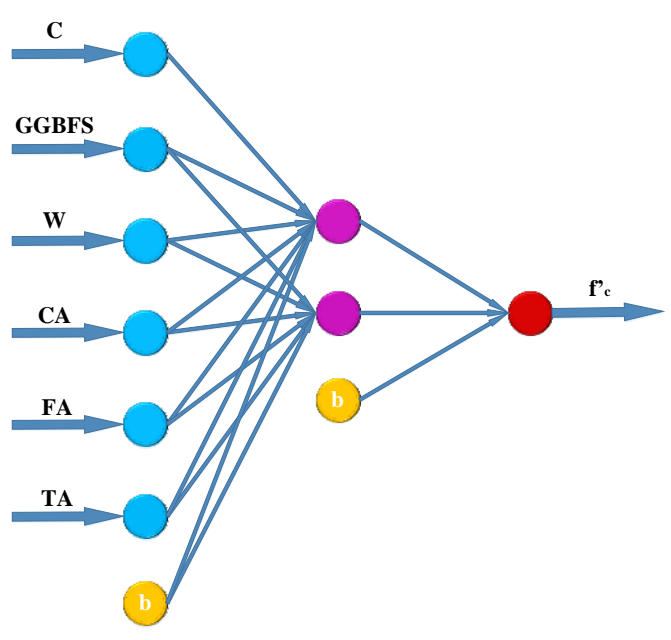

(A)

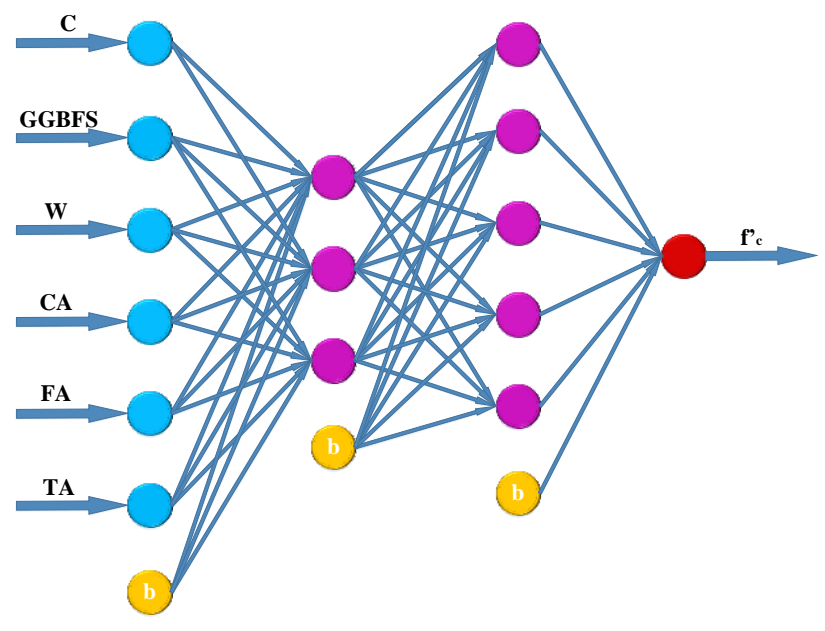

(B)

Figure 4 Architectures of (A) ANN-3 and (B) ANN-7.

To have a good comparison, the results of ANN-7 and ANN-7 were compared with the results of M5P model tree. The obtained tree model is shown in Fig. 5 and the predicted coefficients for the M5P model tree are given in Table 5. 


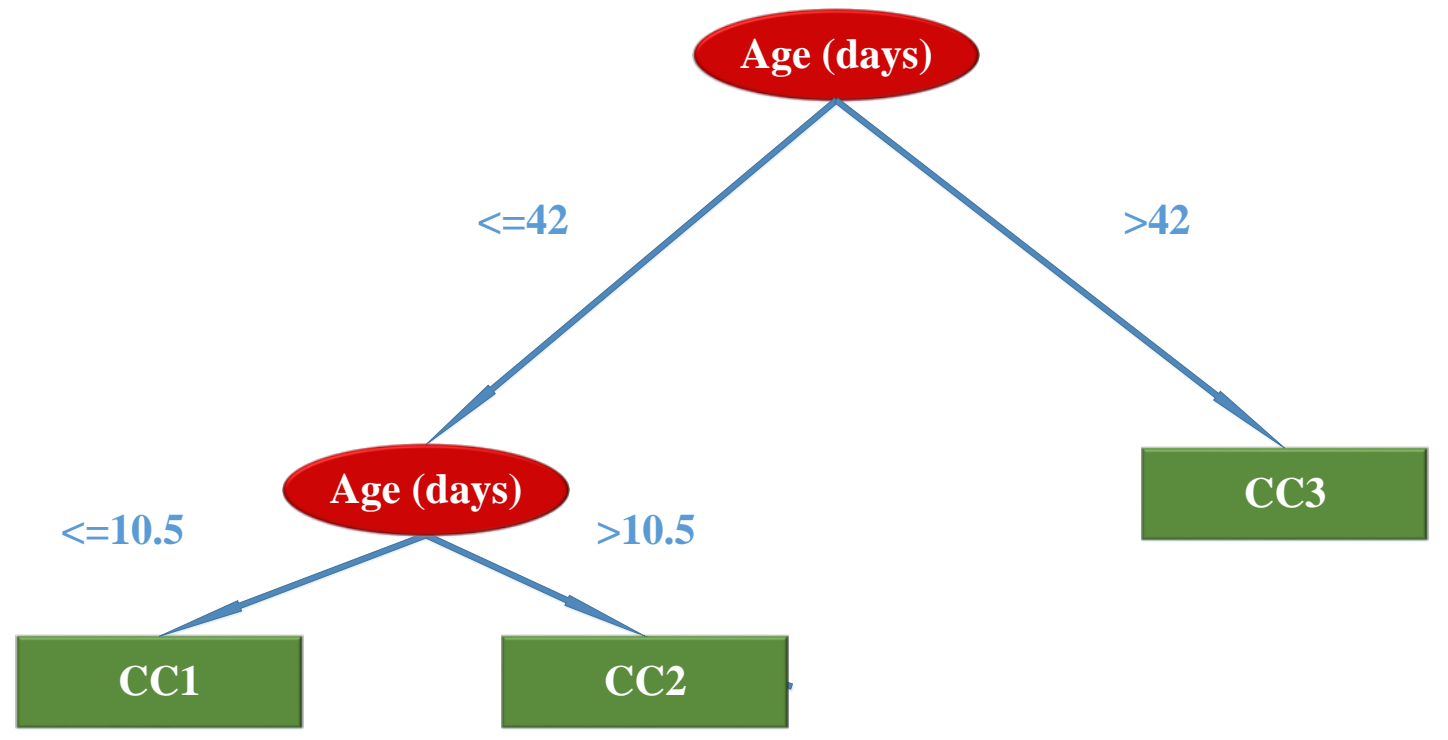

Figure 5 Regression M5P model tree for CC of concrete containing GGBFS.

Table 5 Predicted coefficients for the M5P model tree.

\begin{tabular}{cccccccc}
\hline \multirow{2}{*}{ Linear models } & \multicolumn{7}{c}{ Coefficients } \\
\cline { 2 - 7 } & OPC & W & GGBFS & CA & FA & TA & Bias \\
\hline CC1 & -0.0055 & 0 & -0.0039 & -0.0057 & 0 & 0.0527 & 8.5695 \\
CC2 & -0.0069 & 0 & -0.0046 & -0.0082 & 0 & 0.0262 & 12.0212 \\
CC3 & -0.0112 & -0.0274 & -0.0069 & -0.0133 & 0 & 0.0102 & 24.4885 \\
\hline
\end{tabular}

ANN7 has the RMSE, MAE, MAPE, and OBJ value of $0.055,0.041,4.789$, and 0.084 , respectively, which are the lowest values among the three models. These values of ANN3 are more by $165 \%, 56 \%, 160 \%$, and $49 \%$, respectively in comparison with ANN7, which make it the second accurate model. In contrast to ANN7, M5P tree has the highest value of the same parameter. These values for M5P tree are 0.184 , $0.110,17.869$, and 0.233 , respectively. According to R-value, ANN7 has the best match between predicted and experimental values and ANN3 and M5P tree are the second and the third, respectively. SI indicators represent ANN7 has an excellent performance while two other models have good performances. Furthermore, MBE indicates ANN7, in contrast to other models, underestimates the creep coefficient of concrete containing GGBFS.

Table 6 The statistical indicators of ANN-7, ANN-3, and M5P tree models.

\begin{tabular}{cccccccc}
\hline Models & $\begin{array}{c}\text { RMSE } \\
(\mathrm{MPa})\end{array}$ & $\begin{array}{c}\text { MAE } \\
(\mathrm{MPa})\end{array}$ & $\begin{array}{c}\text { MAPE } \\
(\%)\end{array}$ & $\mathrm{R}$ & $\mathrm{SI}$ & $\begin{array}{c}\text { MBE } \\
(\mathrm{MPa})\end{array}$ & $\begin{array}{c}\text { OBJ } \\
(\mathrm{MPa})\end{array}$ \\
\hline ANN3 & 0.146 & 0.064 & 12.458 & 0.98 & 0.105 & 0.002 & 0.125 \\
ANN7 & 0.055 & 0.041 & 4.789 & 1.00 & 0.040 & -0.003 & 0.084 \\
M5P & 0.184 & 0.110 & 17.869 & 0.97 & 0.134 & 0.014 & 0.233 \\
\hline
\end{tabular}


The predicted CCs of the three developed models are depicted versus experimental results in the Fig. 6. As it can be seen, in ANN7 the dispersion of observations around the baseline is more than ANN3 and M5P, which represents its ability in the learning and generalization phases.
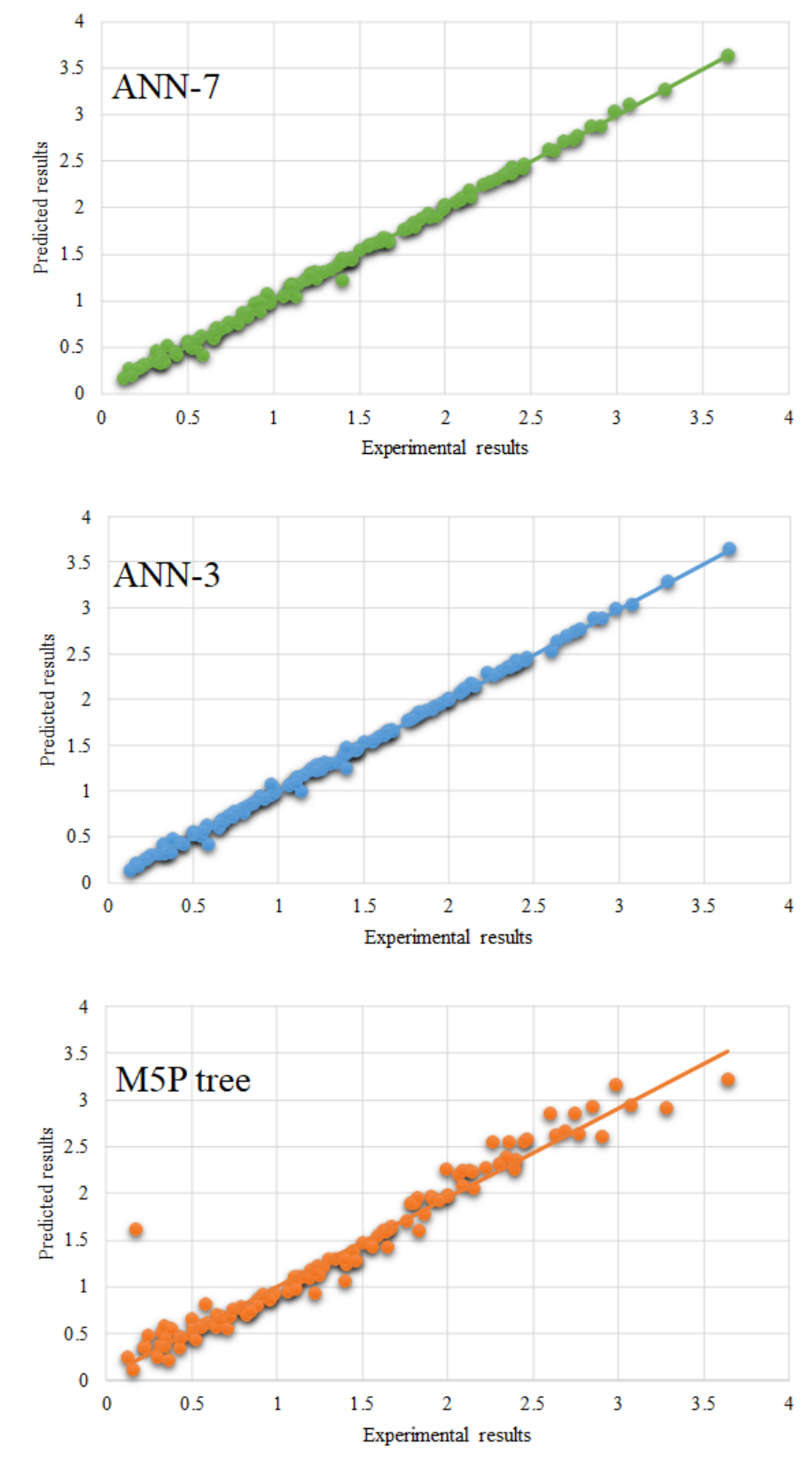

Figure 6 Predicted results vs experimental results of the developed models for training and testing datasets.

To compare the statistical indicators simultaneously, Taylor diagram was used to show the performance of various developed models in terms of RMSE, Correlation coefficient, and standard deviation. There is a baseline in this diagram where a more efficient model will have the closest distance to this line. To compare the performance of the ANN3, ANN7, and M5P models, Fig. 7 demonstrates the Taylor diagram of these three developed models. As can be seen, the closest model to the baseline is related 
to the ANN-7 model, and the second closest one is the ANN-3 model while the M5P model tree is the third one.

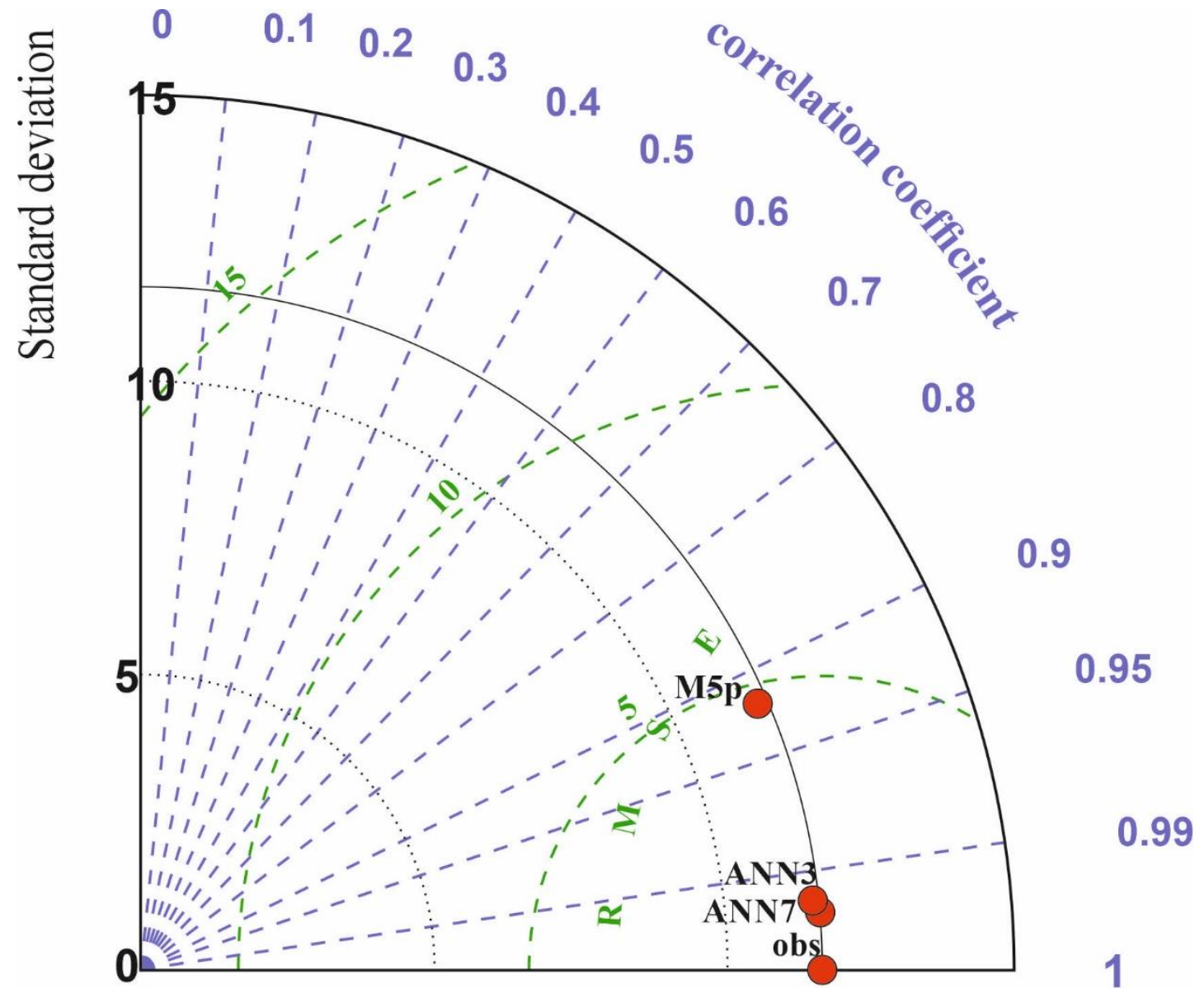

Figure 7 Taylor diagram of three developed models.

All developed models are mathematical functions, which map the constituents of concrete with GGBFS to its creep coefficient. Civil engineers can easily use the decision tree structure of Fig. 5 and the weights and biases of the proposed models in the Appendix to estimate the CC of concrete with GGBFS. They can assume some values for concrete constituents and compute the CC. With trial and error and some changes in the concrete constituents, they can reach to the optimized mix design of concrete with GGBFS. Also, reducing environmental impact of concrete had been approached by many studies by utilizing the use of high quality recycled aggregate as well which can be recommended for the future studies [39-41].

\section{Conclusions}

An ANN model for the prediction of the creep coefficient of concretes containing GGBFS, which accounts for both accuracy and simplicity, can be useful to save in energy, time, and cost. In this research, the multi-objective artificial neural network (MOANN) was proposed in which the 
architecture of ANN was optimized by the multi-objective salp swarm optimization algorithm and then served in predicting the concrete CC with GGBFS. The following findings were drawn in this study:

- The total Pareto front includes 11 ANNs a variety of accuracy and complexity, which let the user to choose a network according to their requirements.

- Ten ANNs out of Pareto front's 11 non-dominated ANNs have the R-value more than 0.9, which deputes the great correlation between the experimental and predicted results.

- The ANN model without any hidden layer is the simplest and the least accurate one and the ANN11 model with 6-5-10-7-1 architecture and 180 links is the most complicated and accurate one.

- Comparing the performance of the two chosen ANN models with the M5P model tree indicates that the performance of ANN- $\backslash 3$ is better than M5P tree performance almost in all areas.

\section{References}

[1] C. Chen, G. Habert, Y. Bouzidi, A. Jullien, Environmental Impact of Cement Production: Detail of The Different Processes and Cement Plant Variability Evaluation, J. Clean. Prod. 18 (2010) 478-485. doi:10.1016/j.jclepro.2009.12.014.

[2] C. Li, X. Gong, S. Cui, Z. Wang, Y. Zheng, B. Chi, CO2 emissions due to cement manufacture, Mater. Sci. Forum. 685 (2011) 181-187. doi:10.4028/www.scientific.net/MSF.685.181.

[3] J. Peng, L. Huang, Y. Zhao, P. Chen, L. Zeng, W. Zheng, Modeling of carbon dioxide measurement on cement plants, Adv. Mater. Res. 610-613 (2013) 2120-2128. doi:10.4028/www.scientific.net/AMR.610-613.2120.

[4] K.P. Verian, A. Behnood, Effects of deicers on the performance of concrete pavements containing air-cooled blast furnace slag and supplementary cementitious materials, Cem. Concr. Compos. 90 (2018) 27-41.

[5] C. Meyer, The greening of the concrete industry, Cem. Concr. Compos. 31 (2009) 601-605. doi:http://dx.doi.org/10.1016/j.cemconcomp.2008.12.010. 
[6] C. Bilim, C.D. Atiş, H. Tanyildizi, O. Karahan, Predicting the compressive strength of ground granulated blast furnace slag concrete using artificial neural network, Adv. Eng. Softw. (2009). doi:10.1016/j.advengsoft.2008.05.005.

[7] I. Yüksel, T. Bilir, Ö. Özkan, Durability of concrete incorporating non-ground blast furnace slag and bottom ash as fine aggregate, Build. Environ. 42 (2007) 2651-2659. doi:10.1016/j.buildenv.2006.07.003.

[8] M.L. Berndt, Properties of sustainable concrete containing fly ash, slag and recycled concrete aggregate, Constr. Build. Mater. 23 (2009) 2606-2613. doi:10.1016/j.conbuildmat.2009.02.011.

[9] A.K. Saha, P.K. Sarker, Expansion due to alkali-silica reaction of ferronickel slag fine aggregate in OPC and blended cement mortars, Constr. Build. Mater. 123 (2016) 135-142. doi:10.1016/j.conbuildmat.2016.06.144.

[10] S. Mirjalili, A.H. Gandomi, S.Z. Mirjalili, S. Saremi, H. Faris, S.M. Mirjalili, Salp Swarm Algorithm: A bio-inspired optimizer for engineering design problems, Adv. Eng. Softw. (2017). doi:10.1016/j.advengsoft.2017.07.002.

[11] A. Kandiri, E. Mohammadi Golafshani, A. Behnood, Estimation of the compressive strength of concretes containing ground granulated blast furnace slag using hybridized multi-objective ANN and salp swarm algorithm, Constr. Build. Mater. (2020). doi:10.1016/j.conbuildmat.2020.118676.

[12] A. Behnood, E.M. Golafshani, Machine learning study of the mechanical properties of concretes containing waste foundry sand, Constr. Build. Mater. (2020). doi:10.1016/j.conbuildmat.2020.118152.

[13] A. Behnood, V. Behnood, M. Modiri Gharehveran, K.E. Alyamac, Prediction of the compressive strength of normal and high-performance concretes using M5P model tree algorithm, Constr. Build. Mater. 142 (2017). doi:10.1016/j.conbuildmat.2017.03.061.

[14] I.B. Topçu, M. Sarıdemir, Prediction of compressive strength of concrete containing fly ash using artificial neural networks and fuzzy logic, Comput. Mater. Sci. (2008). doi:10.1016/j.commatsci.2007.04.009.

[15] U. Atici, Prediction of the strength of mineral admixture concrete using multivariable regression analysis and an artificial neural network, Expert Syst. Appl. (2011). doi:10.1016/j.eswa.2011.01.156.

[16] B.K.R. Prasad, H. Eskandari, B.V.V. Reddy, Prediction of compressive strength of SCC and HPC with high volume fly ash using ANN, Constr. Build. Mater. (2009). doi:10.1016/j.conbuildmat.2008.01.014.

[17] M. Sarıdemir, I.B. Topçu, F. Özcan, M.H. Severcan, Prediction of long-term effects of GGBFS on compressive strength of concrete by artificial neural networks and fuzzy logic, Constr. Build. Mater. (2009). doi:10.1016/j.conbuildmat.2008.07.021.

[18] S. Chithra, S.R.R.S. Kumar, K. Chinnaraju, F. Alfin Ashmita, A comparative study on the compressive strength prediction models for High Performance Concrete containing nano silica and copper slag using regression analysis and Artificial Neural Networks, Constr. Build. Mater. (2016). doi:10.1016/j.conbuildmat.2016.03.214. 
[19] A.T.A. Dantas, M. Batista Leite, K. De Jesus Nagahama, Prediction of compressive strength of concrete containing construction and demolition waste using artificial neural networks, Constr. Build. Mater. (2013). doi:10.1016/j.conbuildmat.2012.09.026.

[20] M. Pala, E. Özbay, A. Öztaş, M.I. Yuce, Appraisal of long-term effects of fly ash and silica fume on compressive strength of concrete by neural networks, Constr. Build. Mater. (2007). doi:10.1016/j.conbuildmat.2005.08.009.

[21] M. Uysal, H. Tanyildizi, Predicting the core compressive strength of self-compacting concrete (SCC) mixtures with mineral additives using artificial neural network, Constr. Build. Mater. (2011). doi:10.1016/j.conbuildmat.2010.11.108.

[22] E.M. Golafshani, G. Pazouki, Predicting the compressive strength of self-compacting concrete containing fly ash using a hybrid artificial intelligence method, Comput. Concr. (2018). doi:10.12989/cac.2018.22.4.419.

[23] F. Özcan, C.D. Atiş, O. Karahan, E. Uncuoğlu, H. Tanyildizi, Comparison of artificial neural network and fuzzy logic models for prediction of long-term compressive strength of silica fume concrete, Adv. Eng. Softw. (2009). doi:10.1016/j.advengsoft.2009.01.005.

[24] A. Behnood, E.M. Golafshani, Predicting the compressive strength of silica fume concrete using hybrid artificial neural network with multi-objective grey wolves, J. Clean. Prod. (2018). doi:10.1016/j.jclepro.2018.08.065.

[25] E.M. Golafshani, A. Behnood, Estimating the optimal mix design of silica fume concrete using biogeography-based programming, Cem. Concr. Compos. 96 (2019) 95-105.

[26] A.J. Tenza-Abril, Y. Villacampa, A.M. Solak, F. Baeza-Brotons, Prediction and sensitivity analysis of compressive strength in segregated lightweight concrete based on artificial neural network using ultrasonic pulse velocity, Constr. Build. Mater. (2018).

doi:10.1016/j.conbuildmat.2018.09.096.

[27] M.M. Alshihri, A.M. Azmy, M.S. El-Bisy, Neural networks for predicting compressive strength of structural light weight concrete, Constr. Build. Mater. (2009).

doi:10.1016/j.conbuildmat.2008.12.003.

[28] Ł. Sadowski, M. Piechówka-Mielnik, T. Widziszowski, A. Gardynik, S. Mackiewicz, Hybrid ultrasonic-neural prediction of the compressive strength of environmentally friendly concrete screeds with high volume of waste quartz mineral dust, J. Clean. Prod. (2019). doi:10.1016/j.jclepro.2018.12.059.

[29] H. Naderpour, A.H. Rafiean, P. Fakharian, Compressive strength prediction of environmentally friendly concrete using artificial neural networks, J. Build. Eng. (2018). doi:10.1016/j.jobe.2018.01.007.

[30] M.A. Getahun, S.M. Shitote, Z.C. Abiero Gariy, Artificial neural network based modelling approach for strength prediction of concrete incorporating agricultural and construction wastes, Constr. Build. Mater. (2018). doi:10.1016/j.conbuildmat.2018.09.097.

[31] J. Xu, X. Zhao, Y. Yu, T. Xie, G. Yang, J. Xue, Parametric sensitivity analysis and modelling of mechanical properties of normal- and high-strength recycled aggregate concrete using grey theory, multiple nonlinear regression and artificial neural networks, Constr. Build. Mater. (2019). doi:10.1016/j.conbuildmat.2019.03.234. 
[32] A. Behnood, J. Olek, M.A. Glinicki, Predicting modulus elasticity of recycled aggregate concrete using M5' model tree algorithm, Constr. Build. Mater. (2015). doi:10.1016/j.conbuildmat.2015.06.055.

[33] E.M. Golafshani, A. Behnood, Automatic regression methods for formulation of elastic modulus of recycled aggregate concrete, Appl. Soft Comput. J. 64 (2018). doi:10.1016/j.asoc.2017.12.030.

[34] E.M. Golafshani, A. Behnood, Application of soft computing methods for predicting the elastic modulus of recycled aggregate concrete, J. Clean. Prod. (2017). doi:10.1016/j.jclepro.2017.11.186.

[35] A. Behnood, K.P. Verian, M. Modiri Gharehveran, Evaluation of the splitting tensile strength in plain and steel fiber-reinforced concrete based on the compressive strength, Constr. Build. Mater. 98 (2015) 519-529. doi:10.1016/j.conbuildmat.2015.08.124.

[36] E.M. Golafshani, A. Ashour, Prediction of self-compacting concrete elastic modulus using two symbolic regression techniques, Autom. Constr. 64 (2016) 7-19. doi:http://dx.doi.org/10.1016/j.autcon.2015.12.026.

[37] A. Behnood, E.M. Golafshani, Machine learning study of the mechanical properties of concretes containing waste foundry sand, Constr. Build. Mater. 243 (2020) 118152. doi:https://doi.org/10.1016/j.conbuildmat.2020.118152.

[38] M. Shariq, J. Prasad, H. Abbas, Creep and drying shrinkage of concrete containing GGBFS, Cem. Concr. Compos. (2016). doi:10.1016/j.cemconcomp.2016.02.004.

[39] F. Sartipi, "Automatic sorting of recycled aggregate using image processing and object detection," Journal of Construction Materials, vol. 1, pp. 3-3, 2020, doi: https://doi.org/10.36756/JCM.v1.2.1.

[40] F. Sartipi and M. Soomro, "Solutions for barriers against the wider use of recycled aggregate."

[41] A. Todhunter, M. Crowley, M. Gholamisheverini, and F. Sartipi, "Advanced technological implementation of construction and demolition waste recycling," Journal of Construction Materials, vol. 1, no. 1, 2019, doi: https://doi.org/10.36756/JCM.v1.1.3. 


\section{Appendix}

Weights and biases of the ANN7 model

Input layer weigths matrix

$$
=\left[\begin{array}{ccccccc}
-2.149 & -0.431 & -3.510 & 3.593 & -3.294 & 3.419 & -0.461 \\
-0.259 & 0.126 & -0.327 & 1.528 & 1.143 & -0.597 & -0.204 \\
-0.197 & -0.091 & -0.006 & -0.015 & -0.312 & 0.147 & -12.260
\end{array}\right]
$$

Input layer bias vector $=\left[\begin{array}{lll}2.411 & -1.390 & -14.056\end{array}\right]$

Output layer weights vector $=\left[\begin{array}{lll}0.396 & -0.986 & -13.700\end{array}\right]$

Output layer bias $=[-14.303]$

Weights and biases of the ANN16 model

Input layer weigths matrix

$$
=\left[\begin{array}{ccccccc}
0.120 & 0.822 & -0.165 & -0.283 & -0.124 & 0.008 & -6.184 \\
0.106 & 1.673 & -0.627 & 2.444 & 1.281 & 2.461 & -0.065 \\
0.228 & 1.176 & -0.247 & -0.361 & -0.160 & 0.169 & 0.239 \\
-0.104 & -0.706 & 0.251 & -0.784 & -2.916 & 4.898 & 0.026 \\
0.423 & -1.013 & 0.787 & -2.137 & -0.478 & -1.844 & 0.064
\end{array}\right]
$$

Input layer bias vector $=\left[\begin{array}{lllll}-5.745 & 0.631 & 0.464 & 2.713 & -0.048\end{array}\right]$

Hidden layer weights matrix $=\left[\begin{array}{ccccc}0.405 & -1.789 & -0.307 & -0.596 & -1.773 \\ -0.266 & -1.676 & 0.236 & -5.974 & -1.106 \\ -9.595 & -0.490 & 7.149 & -0.850 & 0.058 \\ -1.273 & 0.671 & 1.821 & -0.158 & 1.164\end{array}\right]$

Hidden layer bias vector $=\left[\begin{array}{llll}0.930 & -5.249 & 3.704 & 0.272\end{array}\right]$

Output layer weights vector $=\left[\begin{array}{llll}-1.302 & -1.522 & 2.896 & 0.297\end{array}\right]$

Output layer bias vector $=[-3.857]$ 